\title{
Eye movements and the perceptual span in silent and oral reading
}

\author{
Jane Ashby • Jinmian Yang • Kris H. C. Evans • \\ Keith Rayner
}

Published online: 24 February 2012

(C) Psychonomic Society, Inc. 2012

\begin{abstract}
Previous research has examined parafoveal processing during silent reading, but little is known about the role of these processes in oral reading. Given that masking parafoveal information slows down silent reading, we asked whether a similar effect also occurs in oral reading. To investigate the role of parafoveal processing in silent and oral reading, we manipulated the parafoveal information available to readers by changing the size of a gaze-contingent moving window. Participants read silently and orally in a one-word window and a three-word window condition as we monitored their eye movements. The lack of parafoveal information slowed reading speed in both oral and silent reading. However, the effects of parafoveal information were larger in silent reading than in oral reading, because of different effects of preview information on both when the eyes move and how often. Parafoveal information benefitted silent reading for faster readers more than for slower readers.
\end{abstract}

Keywords Eye movements · Parafoveal processing . Oral reading $\cdot$ Reading speed $\cdot$ Individual differences . Slow readers

\author{
J. Ashby $(\square)$ \\ Department of Psychology, \\ Central Michigan University, \\ e-mail: jane.ashby@cmich.edu \\ J. Yang \\ University of California, \\ San Diego, California, USA \\ K. H. C. Evans \\ University of Massachusetts, \\ Amherst, Massachusetts, USA \\ K. Rayner \\ University of California, \\ San Diego, California, USA
}

137 Sloan Hall, Mount Pleasant, MI 48859, USA
One intriguing finding in eye movement research is that word identification processes begin before the eyes fixate a word (Dodge, 1907; Rayner, 1975; Schotter, Angele, \& Rayner, 2012). Readers process the word they are fixating and, at some point during that fixation, begin processing the upcoming word to its right. Thus, word recognition during silent reading typically begins when a word appears in parafoveal view to the right of where the eye is fixated. One surprising aspect of parafoveal processing is that skilled readers activate complex linguistic information such as phonological structure, in addition to processing low-level visual information (Ashby \& Martin, 2008; Ashby \& Rayner, 2004). Parafoveal processes occur automatically during skilled silent reading, and readers appear to be unaware of the parafoveal information they process (Henderson, Dixon, Petersen, Twilley, \& Ferreira, 1995; Lesch \& Pollatsek, 1998; Pollatsek, Lesch, Morris, \& Rayner, 1992; Schotter et al., 2012). Most importantly, parafoveal information enables skilled readers to process text $20-40 \%$ faster than when parafoveal information is not available (Rayner, 1998, 2009; Rayner, Liversedge, \& White, 2006). Parafoveal information contributes to faster reading speed through a reduction in both the duration and number of fixations that occur during skilled silent reading (Rayner, 2009; Fitzsimmons \& Drieghe, 2011).

Although there is substantial research literature examining parafoveal processing during silent reading (see Rayner, 1998, 2009; Schotter et al., 2012), little is known about the role of these processes in oral reading. In this article, we present an initial investigation into the role of parafoveal information in oral reading as compared with silent reading. Given that masking parafoveal information slows down silent reading, we asked whether the availability of parafoveal information affects oral reading in a similar fashion. To do this, we monitored eye movements as participants read sentences silently and orally in conditions in which parafoveal information was and was not available. Beyond contributing to our understanding of oral 
reading processes, these data provide information about the nature of parafoveal processing by examining whether parafoveal effects are vulnerable to task demands and how reading systems uptake available parafoveal information.

Oral reading provides an interesting test of parafoveal processing, since there is little strategic benefit to speeding the rate at which the eyes move when reading aloud. This is partly because of the fact that word pronunciation involves muscles in the speech tract, which operate more slowly than do cognitive processes. As a result of this timing difference, readers typically look at and process a word in the text that is two to three words to the right of the one they are pronouncing (Inhoff, Solomon, Radach, \& Seymour, 2011). Given that the eyes are ahead of the voice in oral reading, readers may only need to process the fixated word, and words to the right of that might be irrelevant.

Classic research suggests a fairly straightforward relationship between silent and oral modes of reading, indicating that oral reading processes may be essentially the same as silent reading processes, with the addition of articulatory demands (Huey, 1908/1968). The few eye movement studies that have been conducted to examine oral and silent reading indicate that eye movements in both reading modes are tightly correlated within participants (Anderson \& Swanson, 1937; Søvik, Arntzen, \& Samuelstuen, 2000).

To investigate parafoveal processes in oral reading as compared with silent reading, we manipulated the parafoveal information available to readers as they read orally and silently by changing the size of a gaze-contingent text window (see Fig. 1) in a moving window paradigm (McConkie \& Rayner, 1975; Rayner \& Bertera, 1979; Rayner, Slattery, \& Bélanger, 2010). In the one-word window (1 W) condition, participants saw the fixated foveal word only. The three-word window $(3 \mathrm{~W})$ allowed readers to obtain parafoveal information; the fixated word and the two words to its right were available in the window ${ }^{1}$. In both conditions, the window moved with each saccade as the eyes advanced through the sentence. As was outlined above, we anticipated three possible outcomes. First, since the eyes are ahead of the voice in oral reading, perhaps only the fixated word is necessary to maintain reading speed, and the $1 \mathrm{~W}$ and $3 \mathrm{~W}$ conditions should not differ. Second, since parafoveal processing occurs automatically during skilled reading, restricting parafoveal information should slow reading down to a comparable extent in both reading tasks. Third, reading might be faster with the $3 \mathrm{~W}$ window than with the $1 \mathrm{~W}$ window, but the amount of preview benefit might be greater in silent reading than in oral reading. Our data were largely consistent with the third prediction.

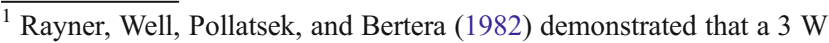
window yielded reading times that were comparable to a no window control condition.
}

\section{Method}

Participants

Twenty-four undergraduates at the University of Massachusetts received either course credit or $\$ 7$ to participate in the experiment. They had normal or corrected-to-normal vision and were naive concerning the experiment's purpose.

\section{Apparatus}

Materials were presented on a 22-in. monitor attached to a Pentium 166 MHZ computer interfaced with an SR Research EyeLink 1000 eye tracking system with high spatial resolution and a sampling rate of $1,000 \mathrm{~Hz}$. Participants read sentences binocularly, but only the right eye was recorded. Viewing distance was approximately $60 \mathrm{~cm}\left(3.8\right.$ letters $=1^{\circ}$ visual angle). Custom designed software ensured that the display change occurred within 6-12 ms; the window appeared to the participants to move in synchrony with their eye movements.

\section{Materials}

Participants read 80 sentences from Rayner, Castelhano, and Yang (2009) presented in Courier, a monospace font. On average, these sentences contained 11.2 words and were 63.5 letters long (including interword spaces). Average word length was 4.8 letters. Average window size (including interword spaces) was 5.8 and 15.5 letter spaces in the $1 \mathrm{~W}$ window and $3 \mathrm{~W}$ window, respectively. Twenty sentences were followed by a yes/no comprehension question, which participants answered with a button press (mean accuracy = $94 \%$ with no difference across conditions).

\section{Design and procedure}

Each participant read a block of 40 sentences silently and a block of another 40 sentences aloud in this withinparticipants, fully counterbalanced design. Sentences with $1 \mathrm{~W}$ and $3 \mathrm{~W}$ windows were randomly interleaved in both blocks. Every participant read one quarter of the sentences in each condition in this $2(1 \mathrm{~W}$ or $3 \mathrm{~W}) \times 2$ (silent or oral) design. Across participants, every sentence appeared in all four reading conditions. To create the window conditions, letters outside the viewing window were replaced by an $\mathrm{x}$ mask for every word in order to preserve low-level parafoveal information about the interword spaces. Example sentences appear in Fig. 1.

Initially, participants were calibrated by fixating on three points randomly presented across the horizontal midline of the screen. At the start of each trial, a square (15 pixels wide) 
Fig. 1 The moving window paradigm. The asterisk $(*)$ indicates the fixation point
Sentence: Kevin reached for Miranda's armband when she moved away from him.

\section{Word Window Condition}

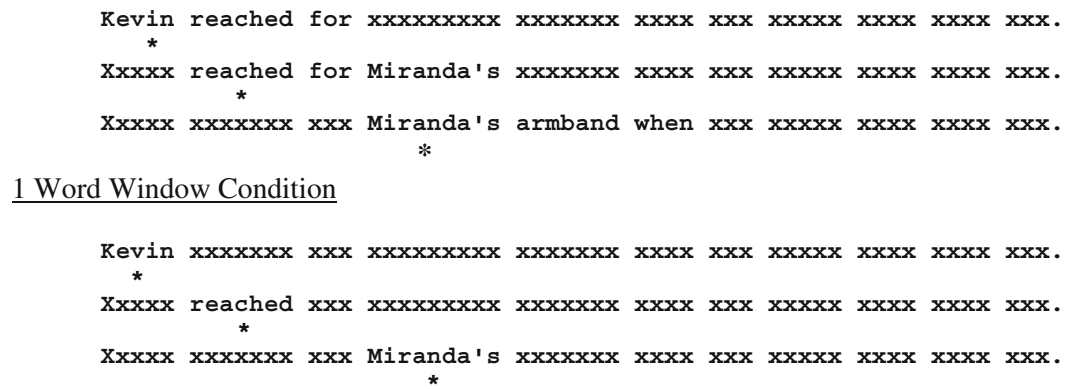

appeared on the left side of the screen, with its left edge aligned with the first letter. The sentence replaced this square on the screen once a stable fixation was detected. Participants were instructed to read for comprehension (either silently or orally) and to press a keypad button when finished. Presentation order within each block (silent or oral) was randomized for each participant, and the order of blocks was counterbalanced across participants. Following the eight practice sentences, participants

Table 1 Results of significance tests for main effects of reading mode and window size as well as the interactions. Tests that were nonsignificant at an alpha of .05 are noted by an asterisk $(*)$

\section{$F$ Values}

Words read per minute

\begin{tabular}{|c|c|c|}
\hline Reading mode & $F_{1}(1,23)=66.86$ & $F_{2}(1,79)=283.77$ \\
\hline Window size & $F_{1}(1,23)=95.75$ & $F_{2}(1,79)=94.18$ \\
\hline Interaction & $F_{1}(1,23)=28.34$ & $F_{2}(1,79)=108.34$ \\
\hline \multicolumn{3}{|c|}{ Average fixation duration } \\
\hline Reading mode & $F_{1}(1,23)=59.39$ & $F_{2}(1,79)=184.45$ \\
\hline Window size & $F_{1}(1,23)=124.29$ & $F_{2}(1,79)=194.08$ \\
\hline Interaction & $F_{1}(1,23)=9.76$ & $F_{2}(1,79)=13.35$ \\
\hline \multicolumn{3}{|c|}{ Number of fixations per sentence } \\
\hline Reading mode & $F_{1}(1,23)=116.19$ & $F_{2}(1,79)=215.29$ \\
\hline Window size & $F_{1}(1,23)=29.76$ & $F_{2}(1,79)=37.61$ \\
\hline Interaction & $F_{1}(1,23)=12.89$ & $F_{2}(1,79)=10.82$ \\
\hline \multicolumn{3}{|c|}{ Probability of first-pass fixation } \\
\hline Reading mode & $F_{1}(1,23)=35.97$ & $F_{2}(1,79)=110.58$ \\
\hline Window size & $F_{1}(1,23)=96.27$ & $F_{2}(1,79)=121.22$ \\
\hline Interaction & $F_{1}(1,23)=10.04$ & $F_{2}(1,79)=4.67$ \\
\hline \multicolumn{3}{|c|}{ Probability of refixation } \\
\hline Reading mode & $F_{1}(1,23)=76.64$ & $F_{2}(1,79)=113.64$ \\
\hline Window size & $F_{1}(1,23)=14.12$ & $F_{2}(1,79)=22.97$ \\
\hline Interaction & $F_{1}(1,23)=2.33^{*}$ & $F_{2}(1,79)<1^{*}$ \\
\hline \multicolumn{3}{|c|}{ Forward saccade length } \\
\hline Reading mode & $F_{1}(1,23)=44.05$ & $F_{2}(1,79)=201.64$ \\
\hline Window size & $F_{1}(1,23)=75.75$ & $F_{2}(1,79)=83.54$ \\
\hline Interaction & $F_{1}(1,23)=5.82$ & $F_{2}(1,79)=1.93^{*}$ \\
\hline
\end{tabular}

read 80 experimental sentences ( 20 in each of the four experimental conditions).

\section{Results}

Fixations shorter than $80 \mathrm{~ms}$ and longer than $800 \mathrm{~ms}$ were eliminated (.9\% of fixations). Trials in which there was a blink or track loss during reading were removed prior to analysis ( $10 \%$ of trials), as were trials in which the mean eye movement measure fell $2.5 S D$ beyond the participants' mean for a given window size ( $2.6 \%$ of trials). Trial exclusion affected all conditions similarly $(F<1)$.

To be consistent with previous moving window experiments, we first report reading rate, or words read per minute (wpm), which was calculated as the sum of fixation times from the beginning of the first fixation to the end of the last fixation in a sentence. Because reading rate is a composite of fixation durations and number of fixations, we also report average fixation duration, average number of fixations per sentence, and the average length of forward saccades. We chose these measures in order to identify which eye movement behaviors contributed to differences in reading rate. In addition, the probability of first fixation and the probability of refixation were examined in order to determine whether an effect found in number fixations was due to these measures ${ }^{2}$.

In all eye movement measures, we found the expected main effects of reading mode and window size (all $p$ s < .001) reported in previous articles (see Tinker, 1936; Rayner, 2009), and the $F$ values for these appear in Table $1^{3}$. In addition to main effects, Table 1 presents tests of interactions between reading mode and window size that suggest that the

\footnotetext{
${ }^{2}$ We thank Ralph Radach for this suggestion.

${ }^{3}$ Main effects of reading mode included faster reading in silent than oral reading (249 wpm and $190 \mathrm{wpm}$, respectively), accompanied by fewer fixations (11.04 vs. 13.11) and longer saccades (7.26 vs. 6.4 letter spaces). Main effects of window size included faster reading in the larger than the smaller window condition (238 wpm and $200 \mathrm{wpm}$, respectively) with fewer fixations (11.68 vs. 12.47$)$ and longer saccades ( 7.25 vs. 6.41 letter spaces).
} 
Table 2 Participant means and standard errors for the one word (1 W) and three word $(3 \mathrm{~W})$ windows in the silent and oral reading conditions

\begin{tabular}{|c|c|c|c|c|}
\hline & \multicolumn{2}{|c|}{ Silent Reading } & \multicolumn{2}{|c|}{ Oral Reading } \\
\hline & $M$ & $S E$ & $M$ & $S E$ \\
\hline \multicolumn{5}{|c|}{ Words read per minute } \\
\hline $3 \mathrm{~W}$ window & 278 & 12 & 198 & 5 \\
\hline $1 \mathrm{~W}$ window & 219 & 10 & 182 & 5 \\
\hline \multicolumn{5}{|c|}{ Fixation duration (ms) } \\
\hline $3 \mathrm{~W}$ window & 244 & 5 & 273 & 4 \\
\hline $1 \mathrm{~W}$ window & 274 & 6 & 291 & 5 \\
\hline \multicolumn{5}{|c|}{ Number of fixations } \\
\hline $3 \mathrm{~W}$ window & 10.41 & .37 & 12.94 & .37 \\
\hline $1 \mathrm{~W}$ window & 11.66 & .32 & 13.27 & .34 \\
\hline \multicolumn{5}{|c|}{ Probability of first-pass fixation } \\
\hline $3 \mathrm{~W}$ window & 70 & .02 & .76 & .01 \\
\hline $1 \mathrm{~W}$ window & .79 & .01 & .82 & .01 \\
\hline \multicolumn{5}{|c|}{ Probability of refixation } \\
\hline $3 \mathrm{~W}$ window & 10 & .01 & .17 & .01 \\
\hline $1 \mathrm{~W}$ window & .13 & .01 & .19 & .01 \\
\hline \multicolumn{5}{|c|}{ Saccade length (letter spaces) } \\
\hline $3 \mathrm{~W}$ Window & 7.76 & .27 & 6.75 & .21 \\
\hline $1 \mathrm{~W}$ Window & 6.76 & .23 & 6.05 & .16 \\
\hline
\end{tabular}

availability of parafoveal information had larger effects in silent versus oral reading. Therefore, we describe the followup $t$ tests in the following text.

\section{Reading rate}

As Table 2 illustrates, having parafoveal information available to the right of fixation increased reading speed more in the silent than in the oral reading conditions. However, paired $t$ tests confirmed a significant preview effect in both silent

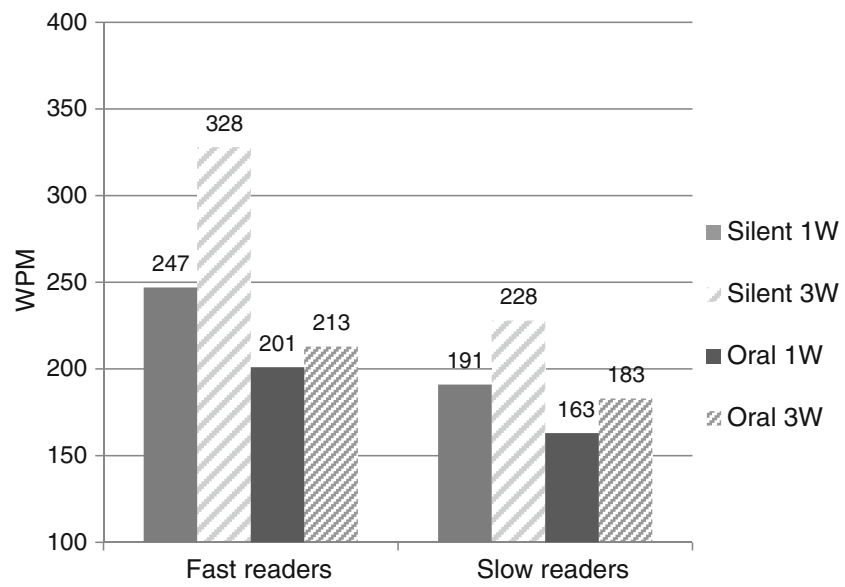

Fig. 2 Words read per minute (WPM) by fast and slow readers during silent reading (one word window [1 W] and three word window [3 W]) and oral reading ( $1 \mathrm{~W}$ and $3 \mathrm{~W}$ ) reading, $t_{1}(23)=8.10, p<.001 ; t_{2}(79)=8.80, p<.001$, and oral reading, $t_{l}(23)=5.18, p<.001 ; t_{2}(79)=4.93, p<.001$.

Following Rayner et al. (2010), we did a median split of the data according to participants' silent reading rates in the $3 \mathrm{~W}$ condition, yielding a fast group (mean wpm $=328 \mathrm{wpm}$ ) and a slow group (mean $=228 \mathrm{wpm})$. In addition to finding that the pattern of effects noted above held for each group, statistical tests confirmed a three-way interaction, $F_{1}(1,22)=$ $18.38, p<.001 ; F_{2}(1,61)=20.91, p<.001$, driven by stronger preview benefits in silent reading for the faster readers than the slower readers (see Fig. 2). In addition, follow-up tests of window size were significant for both groups in both conditions: faster readers during silent reading, $t_{l}(11)=7.34$, $p<.001 ; t_{2}(78)=9.73, p<.001$, and oral reading, $t_{l}(11)=$ $2.59, p<.05 ; t_{2}(77)=2.11, p<.05$; slower readers during silent reading, $t_{1}(11)=9.60, p<.001 ; t_{2}(73)=8.18, p<.001$, and oral reading, $t_{1}(11)=5.05, p<.001 ; t_{2}(69)=3.43, p<.001$.

Fixation duration

As seen in Table 2, the average fixation duration decreased when parafoveal information was available, as compared with when it was not, in both the silent and oral reading conditions (a difference of $30 \mathrm{~ms}$ and $18 \mathrm{~ms}$, respectively). This effect was significantly larger in silent than in oral reading (Table 1), but follow-up paired $t$ tests confirmed a significant preview effect in both silent reading, $t_{l}(23)=$ $9.60, p<.001 ; t_{2}(79)=11.69, p<.001$, and oral reading, $t_{l}(23)=6.14, p<.001 ; t_{2}(79)=7.55, p<.001$. Table 3 displays the means for the fast and slow readers; there was no three-way interaction.

Table 3 Participant means for the faster readers and slower readers

\begin{tabular}{|c|c|c|c|c|}
\hline & \multicolumn{2}{|c|}{ Faster Readers } & \multicolumn{2}{|c|}{ Slower Readers } \\
\hline & $\begin{array}{l}\text { Silent } \\
\text { reading }\end{array}$ & $\begin{array}{l}\text { Oral } \\
\text { reading }\end{array}$ & $\begin{array}{l}\text { Silent } \\
\text { reading }\end{array}$ & $\begin{array}{l}\text { Oral } \\
\text { reading }\end{array}$ \\
\hline \multicolumn{5}{|c|}{ Fixation duration (ms) } \\
\hline $3 \mathrm{~W}$ window & 234 & 272 & 254 & 275 \\
\hline $1 \mathrm{~W}$ window & 264 & 286 & 285 & 296 \\
\hline \multicolumn{5}{|c|}{ Number of fixations } \\
\hline $3 \mathrm{~W}$ window & 9.01 & 11.97 & 11.81 & 13.91 \\
\hline $1 \mathrm{~W}$ window & 10.68 & 12.11 & 12.63 & 14.42 \\
\hline \multicolumn{5}{|c|}{ Probability of first pass fixations } \\
\hline $3 \mathrm{~W}$ window & .67 & .75 & .73 & .78 \\
\hline $1 \mathrm{~W}$ window & .76 & .81 & .82 & .83 \\
\hline \multicolumn{5}{|c|}{ Probability of refixations } \\
\hline $3 \mathrm{~W}$ window & .06 & .15 & .14 & .19 \\
\hline $1 \mathrm{~W}$ window & .10 & .16 & .17 & .21 \\
\hline \multicolumn{5}{|c|}{ Saccade Length (letter spaces) } \\
\hline $3 \mathrm{~W}$ Window & 8.42 & 7.00 & 7.11 & 6.50 \\
\hline $1 \mathrm{~W}$ Window & 7.32 & 6.28 & 6.20 & 5.82 \\
\hline
\end{tabular}




\section{Number of fixations}

On average, readers made fewer fixations per sentence when parafoveal information was available than when it was not (see Table 2). This effect was significantly larger in silent versus oral reading (Table1); paired $t$ tests confirmed a significant preview effect in silent reading, $t_{1}(23)=6.41, p<$ $.001 ; t_{2}(79)=5.81, p<.001$, whereas the effect in oral reading was barely marginal by participants, $t_{l}(23)=1.73, p=.098$, and was significant by items, $t_{2}(79)=2.34, p<.05$.

Statistical tests of data from faster and slower readers, as defined above, confirmed a three-way interaction, $F_{1}(1,22)=$ $7.16, p<.05, F_{2}(1,61)=6.24, p<.05$, driven by a larger decrease in the number of fixations made by fast readers when parafoveal information was available, as compared with when it was not. Follow-up tests of parafoveal preview effects were significant for both groups only in the silent reading condition: faster readers, $t_{l}(11)=5.29, p<.001 ; t_{2}(78)=7.19, p<.001$, and slower readers, $t_{l}(11)=5.16, p<.001 ; t_{2}(73)=3.65$, $p<.001$. In contrast, preview availability did not significantly affect the number of fixations made during oral reading by faster readers, $t \mathrm{~s}<1$, or slower readers, $t_{l}(11)=$ $1.53, p=.16, t_{2}(69)=1.14, p>.2$.

\section{Probability of first-pass fixation}

On average, readers were more likely to fixate a word when parafoveal information for that word was unavailable (see Table 2). This effect was significantly larger in silent versus oral reading (Table 1); however, paired $t$ tests confirmed a significant preview effect in silent reading, $t_{l}(23)=9.70$, $p<.001 ; t_{2}(79)=9.12, p<.001$, and in oral reading, $t_{l}(23)=$ $6.68, p<.001 ; t_{2}(79)=8.73, p<.001$. Table 3 presents the means by skill group. Paired $t$ tests confirmed parafoveal preview effects for the faster readers in silent reading, $t_{l}(11)=$ $6.50, p<.001 ; t_{2}(78)=6.63, p<.001$, and in oral reading, $t_{1}(11)=6.11, p<.001 ; t_{2}(77)=6.15, p<.001$. Slower readers also showed a preview effect in silent reading, $t_{l}(11)=6.98, p<$ $.001 ; t_{2}(73)=9.53, p<.001$, and in oral reading, $t_{I}(11)=3.67$, $p<.01 ; t_{2}(69)=6.10, p<.001$, with no three-way interaction.

\section{Probability of refixation}

On average, readers were more likely to refixate a word when parafoveal information for that word was unavailable (see Table 2). A nonsignificant interaction failed to indicate any difference in effect size for silent versus oral reading, and there was no interaction with reading skill $\left(F_{\mathrm{S}}<1\right)$.

Forward saccade length

As seen in Table 2, forward saccades during silent reading were one character shorter on average when parafoveal letter information was unavailable than when it was available. During oral reading, forward saccade length was .71 characters shorter when parafoveal letter information was unavailable. The interaction was significant by participants, but not by items $(p=.17)$. Follow-up paired $t$ tests confirmed significant preview effects in silent reading, $t_{1}(23)=$ $7.96, p<.001 ; t_{2}(79)=6.81, p<.001$, and in oral reading, $t_{1}(23)=6.63, p<.001 ; t_{2}(79)=7.99, p<.001$. A similar pattern held for the fast and slow readers, and there was no significant three-way interaction $\left(F_{\mathrm{S}}<1\right)$.

\section{Results summary}

We found significant main effects of window size and reading mode across all measures, which suggests that parafoveal information plays a role in eye movement control during oral reading as well as silent reading. Significant interactions between reading mode and window size indicated that the effects of parafoveal information availability were larger in silent reading than in oral reading for most measures. The availability of parafoveal information did affect reading rate, fixation duration, and probability of first fixation in oral reading, but less so than in silent reading. Analyses with reading skill as a factor suggested that parafoveal information availability improved reading rate for faster readers during silent reading more than any other condition, and that this benefit for the fast readers was derived mainly from a reduced number of fixations.

\section{Discussion}

In this experiment, we examined parafoveal processing during silent and oral reading. Participants read sentences aloud and silently in conditions in which parafoveal information was available $(3 \mathrm{~W})$ and in which it was not $(1 \mathrm{~W})$. Parafoveal information facilitated reading speed in both reading modes; text was read faster during silent and oral reading when parafoveal information was available than when it was not. In this respect, oral reading processes seem to parallel silent reading processes, as was suggested by previous research (Anderson \& Swanson, 1937; Tinker, 1936). However, the data also revealed stronger parafoveal information effects in silent than in oral reading. In terms of overall reading speed, the availability of parafoveal information improved silent reading speed by 59 wpm, which was more than three times the size of that effect in oral reading $(16 \mathrm{wpm})$. The parafoveal effect on fixation durations was somewhat larger in silent $(30 \mathrm{~ms})$ than in oral $(18 \mathrm{~ms})$ reading. The parafoveal effect on the number of fixations was substantially larger in silent reading (1.25 fewer fixations per sentence) than in oral reading (.33 fewer fixations per sentence). Together, these data suggest that the 
availability of parafoveal information affected both the when and the where systems of eye movement control (e.g., Findlay \& Walker, 1999; Rayner \& McConkie, 1976; Rayner \& Pollatsek, 1981).

The data pattern is consistent with previous studies that established the role of parafoveal processes in facilitating silent reading (Rayner, 2009; Rayner et al. 2006). These data indicate that parafoveal information benefits silent reading by reducing the duration and number of fixations. In addition, in this study, we demonstrated that parafoveal information contributes directly to decreases in fixation duration during oral as well as silent reading. In contrast, the number of fixations on a sentence was reduced when parafoveal information was available during silent reading, but not oral reading. Therefore, the data indicate that most of the benefit of parafoveal information to oral reading speed stems from reduced fixation durations. As a consequence, the overall parafoveal preview benefit was smaller when reading aloud than when reading silently.

We propose three possible interpretations of the reduced effect of parafoveal information in oral reading. First, it may be that the additional phonological working memory processes recruited in oral reading to maintain words awaiting pronunciation (and the addition of production processes) deplete the resources available for parafoveal processing (see Inhoff, Connine, Eiter, Radach, \& Heller, 2004). Second, parafoveal processes might operate similarly in silent and oral reading, but the benefits of parafoveal information could be mitigated downstream. For example, the phonological representations held in working memory for articulation could interfere more with recently activated phonological representations and thereby reduce the parafoveal information benefit during oral reading. However, this does not explain why the availability of parafoveal information had a relatively small effect on the number of fixations in oral reading. Finally, another possible account is that parafoveal information is processed similarly in the two reading modes, but readers do not utilize it to program fixation location during oral reading.

Our finding that parafoveal information speeded silent reading more for faster readers than for slower readers is consistent with Rayner et al. (2010) and with Chace, Rayner, and Well (2005). The latter study reported larger parafoveal phonological effects for more skilled readers than for less skilled readers. On the basis of the foveal load hypothesis (Henderson \& Ferreira, 1990; Kennison \& Clifton, 1995; Rayner, 1986; Schroyens, Vitu, Brysbaert, \& d'Ydewalle, 1999; White, Rayner, Liversedge, 2005), Chace et al. proposed that slower readers devote more resources to foveal processing and therefore have fewer resources available for parafoveal processing than do faster readers. In the present study, the slow readers were less able than the fast readers to process words in the parafovea to support word skipping during silent reading.

In summary, we found that the availability of parafoveal information facilitated oral as well as silent reading. However, parafoveal information speeded silent reading rate more than oral, because of different effects of preview information on when the eyes move and how often. Lastly, the difference in the parafoveal effects on silent and oral reading rate was larger for faster readers than for slower readers.

Author Note This research was supported in part by Grant HD051700 from the National Institute of Child Health and Human Development. We thank Chuck Clifton, Robin Morris, and Ralph Radach for their helpful comments on an earlier version of this manuscript.

\section{References}

Anderson, I. H., \& Swanson, D. E. (1937). Common factors in eye movements in silent and oral reading. Psychological Monographs, 48, 61-69.

Ashby, J., \& Martin, A. E. (2008). Prosodic phonological representations early in visual word recognition. Journal of Experimental Psychology: Human Perception and Performance, 34, 224-236.

Ashby, J., \& Rayner, K. (2004). Representing syllable information in word recognition during silent reading: Evidence from eye movements. Language \& Cognitive Processes, 19, 391-426.

Chace, K. H., Rayner, K., \& Well, A. D. (2005). Eye movements and phonological parafoveal preview: Effects of reading skill. Canadian Journal of Experimental Psychology, 59, 209-217.

Dodge, R. (1907). An experimental study of visual fixation. Psychological Review Monograph Supplement, 4, iv - 92.

Findlay, J. M., \& Walker, R. (1999). A model of saccade generation based on parallel processing and competitive inhibition. The Behavioral and Brain Sciences, 22, 661-721.

Fitzsimmons, G., \& Drieghe, D. (2011). The influence of number of syllables on word skipping during reading. Psychonomic Bulletin \& Review, 18, 736-741.

Henderson, J. M., \& Ferreira, F. (1990). Effects of foveal processing difficulty on the perceptual span in reading: Implications for attention and eye movement control. Journal of Experimental Psychology: Learning, Memory, and Cognition, 16, 417-429.

Henderson, J. M., Dixon, P., Petersen, A., Twilley, L. C., \& Ferreira, F. (1995). Evidence for the use of phonological representations during transsaccadic word recognition. Journal of Experimental Psychology: Human Perception and Performance, 21, 82-97.

Huey, E. B. (1908/1968). Psychology and Pedagogy of Reading. Cambridge, MA: MIT Press.

Inhoff, A. W., Connine, C., Eiter, B., Radach, R., \& Heller, D. (2004). Phonological representation of words in working memory during sentence reading. Psychonomic Bulletin \& Review, 11, 320-325.

Inhoff, A. W., Solomon, M., Radach, R., \& Seymour, B. A. (2011). Temporal dynamics of the eye-voice span and eye movement control during oral reading. Journal of Cognitive Psychology, 23, 643-558.

Kennison, S. M., \& Clifton, C. (1995). Determinants of parafoveal preview benefit in high and low working memory capacity readers: Implications for eye movement control. Journal of Experimental Psychology: Learning, Memory, and Cognition, 21, 68-81.

Lesch, M. F., \& Pollatsek, A. (1998). Evidence for the use of assembled phonology in accessing the meaning of printed words. 
Journal of Experimental Psychology: Learning, Memory, and Cognition, 24, 573-592.

McConkie, G. W., \& Rayner, K. (1975). The span of the effective stimulus during a fixation in reading. Perception \& Psychophysics, 17, 578-586.

Pollatsek, A., Lesch, M., Morris, R. K., \& Rayner, K. (1992). Phonological codes are used in integrating information across saccades in word identification and reading. Journal of Experimental Psychology: Human Perception and Performance, 18, 148-162.

Rayner, K. (1975). The perceptual span and peripheral cues in reading. Cognitive Psychology, 7, 65-81.

Rayner, K. (1986). Eye movements and the perceptual span in beginning and skilled readers. Journal of Experimental Child Psychology, 41, 211-236.

Rayner, K. (1998). Eye movements in reading and information processing: Twenty years of research. Psychological Bulletin, 124, 372422.

Rayner, K. (2009). Eye movements and attention in reading, scene perception, and visual search. Quarterly Journal of Experimental Psychology, 62, 1457-1506.

Rayner, K., \& Bertera, J. H. (1979). Reading without a fovea. Science, 206, 468-469.

Rayner, K., Castelhano, M. S., \& Yang, J. (2009). Eye movements and the perceptual span in older and younger readers. Psychology and Aging, 24, 755-760.

Rayner, K., Liversedge, S. P., \& White, S. J. (2006). Eye movements when reading disappearing text: The importance of the word to the right of fixation. Vision Research, 46, 310-323.
Rayner, K., \& McConkie, G. W. (1976). What guides a reader's eye movements? Vision Research, 16, 829-837.

Rayner, K., \& Pollatsek, A. (1981). Eye movement control during reading: Evidence for direct control. Quarterly Journal of Experimental Psychology, 33, 351-373.

Rayner, K., Slattery, T. J., \& Bélanger, N. N. (2010). Eye movements, the perceptual span, and reading speed. Psychonomic Bulletin \& Review, 17, 834-839.

Rayner, K., Well, A. D., Pollatsek, A., \& Bertera, J. H. (1982). The availability of useful information to the right of fixation in reading. Perception \& Psychophysics, 31, 537-550.

Schotter, E. R., Angele, B., \& Rayner, K. (2012). Parafoveal processing in reading. Attention, Perception, \& Psychophysics, 74, 5-35. doi:10.3758/s13414-011-0219-2

Schroyens, W., Vitu, F., Brysbaert, M., \& d'Ydewalle, G. (1999). Eye movement control during reading: Foveal load and parafoveal processing. Quarterly Journal of Experimental Psychology A: Human Experimental Psychology, 52A, 1021-1046.

Søvik, N., Arntzen, O., \& Samuelstuen, M. (2000). Eye-movement parameters and reading speed: A study of oral and silent reading performances of twelve-year-old children. Reading and Writing, $13,237-255$.

Tinker, M. A. (1936). Time taken by eye-movements in reading. Pedagogical Seminary and Journal of Genetic Psychology, 48, 468-471.

White, S. J., Rayner, K., \& Liversedge, S. P. (2005). Eye movements and the modulation of parafoveal processing by foveal processing difficulty: A reexamination. Psychonomic Bulletin \& Review, 12, 891-896. 